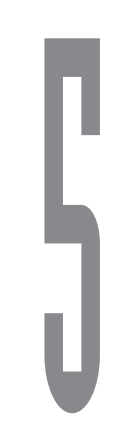

\title{
MANUFACTURING PERFOMANCE: IMPACT OF KAIZEN-BLITZ IMPLEMENTATION IN SEVERAL AUTOMOTIVE COMPONENTS FIRST TIER SUPPLIERS
}

\author{
JUAN A. MARIN-GARCIA \\ JULIO GARCIA-SABATER \\ CRISTOBAL MIRALLES \\ DEPARTAMENTO DE ORGANIZACION DE EMPRESAS \\ UNIVERSIDAD POLITECNICA DEVALENCIA
}

\begin{abstract}
Resumen: The aim of this paper is to explore the possibility of improving production indicators by means of the application of lean production techniques, developed through Kaizen-Blitz teams made up of managers and operators. To this end, the empirical research will consist of the description of the results obtained in 11 industrial companies from the automotive components industry. In each of the companies, we have followed up different interventions over a 9-12 month period. We shall present the initial situation; the activities carried out by the company and the evolution of the manufacturing performance approximately three months after the activities are finished. This will enable us to draw favourable conclusions on these interventions and we shall discuss the degree of congruence with previous research on the subject.
\end{abstract}

Key words: Human resources, productivity and competitiveness, continuous improvement.

\section{Introduction}

Currently, most automobile manufacturers have transformed their philosophy of production in favour of the lean production paradigm. By doing so, they hope to improve efficiency and to obtain better results in the markets in which they operate. This transformation must occur not only in the plants, but it seems important that first tier suppliers should also modify their production systems in line with the lean production philosophy Liker y Wu (2000). In the future, the effects of this wave will probably also reach second level suppliers, with the result that one integrated supply chain can be built.

Nevertheless, in the interventions that we have carried out in recent years in the automobile auxiliary industry, we have been able to observe that the suppliers companies are still not convinced of the profitability of lean systems, in spite of the favourable opinions expressed in scientific publications. One of the main reasons is that they lack information and clear examples related to their activities. For the supplier company managers, the fact that lean production is a success in automobile manufacturers does not guarantee, from the outset, that they too will have this success.

Moreover, for the supplier companies there is no question that the advance towards lean production requires investments, not just in facilities but also in worker training and time to develop the improvements. They are also aware that the way is not free of risks, such as the loss of the buffer provided by stocks or the greater pressure on workers, among others. Some of these risks have been discussed in recent research Cooney (2002), Fairris (2002).

On the other hand, in the academic world it is considered that certain management actions in human 
resources, such as training, teamwork and continuous improvement are undoubtedly important factors, particularly when organisations face a change in how they operate Power y Sohal (2000), Taira (1996).

In this paper we are interested in showing the possibilities for enhancement of industrial processes offered by the implementation of Kaizen-Blitz in companies supplying the automobile manufacturers. The success of the improvement proposals shall be measured on the basis of the variation of specific production indicators. With the aim of isolating the effects that could be produced by the type of process followed to put lean production into action, all the companies were submitted to the same treatment, consisting of the creation of task forces made up of managers and workers, who developed the improvement proposals after receiving specific training.

As proposed by Shah and Ward Shah y Ward (2003), there has been little empirical research to establish the degree of the improvement of productive indicators in companies advancing towards lean production. We believe that the proposed aim of our research may help to fill this gap.

\section{Review of literature}

The Kaizen-Blitz teams as a task forces, are teams that do not form a permanent part of the organisational structure and are involved in a secondary task for their members (Bradford and Bradford, I981; Lawler III, 1996). This task is superimposed upon the habitual obligations of the group members within the company Lawler III et al. (200I).

The main difference compared with other types of groups usually found in the companies, such as quality circles or semi-autonomous groups Glassop (2002), Moses y Stahelski (1999), is that the KaizenBlitz teams are of very limited duration (sometimes less than a week). Moreover Kaizen-Blitz teams are externally managed groups: they only have the responsibility of carrying out the task they have been assigned, and the management designs the group task, select the components, set out the basic rules to achieve the objectives, etc. The management also guides the group task and supervise the group results, as well as designing the organisational context the group is to work in and setting up the reward system and training or information the group is to receive Hackman (1990), Montabon (2005), Rees (1997).

\section{I. Repercussions of Kaizen-Blitz practices on business performance in lean production environments}

In the bibliographical revision carried out, we found several papers on the effect of the use of lean production on the company's results. Many of these make reference to productive indicators and consider that lean production contributes to improving physical productivity (measured as pieces per worker or reduction of cycle time), the quality of products made or the amount of stock necessary in the company Cua et al. (200I), Fullerton et al. (2003), Giffi et al. (1990), Gunn (1992), Lowe et al. (1997), Martínez Sánchez y Pérez Pérez (200I), Maskell (1995), White et al. (1999), Womack et al. (1992). Other indicators which will probably improve with the implementation of lean production are: a reduction in delivery delays, a decrease in products returned by the customers Marín y Delgado (2000), reduction of changeover times Fullerton et al. (2003), Martínez Sánchez y Pérez Pérez (200I), Maskell (1995), reduction in lead time Fullerton et al. (2003), Gunn ( 1992), Martínez Sánchez y Pérez Pérez (200 I), Shah y Ward (2003), White et al. (1999) or a decrease in the space needed in the production area Lowe et al. ( 1997), Womack et al. ( 1992)

To date, not many published papers have been found that attempt to approach the operational outcomes deriving from the use of Kaizen-Blitz, as proposed in our research. The only exceptions are the four papers mentioned in Montabon (2005).

Finally, there are some publications where the joint application of lean production and work teams was evaluated. In these, it was considered that the use of techniques associated with the lean production system (just in time, total productive maintenance or total quality management) substantially enhanced operational performance, while the effects deriving from the participation of the workers in the deployment of that system, rather than following more directly managerial procedures (by unilateral decisions of managers or consultants) are much less pronounced Lowe et al. (1997), Shah y Ward (2003). Nevertheless, the aim of our research is not so ambitious as those researches. We do not attempt to isolate the effect produced by the application of certain lean production techniques from the effect due to the use of ad-hoc groups, but we do aim to quantify the joint effect of developing the implementation of a lean system through groups that allow workers' involvement. 


\section{Research Method}

\section{I. Sample and procedures}

For the empirical research, data was compiled from I I suppliers of one automobile manufacturer.These companies were selected either for their importance by volume of purchase, having achieved cost reductions in recent years, or because they had recently encountered problems relating to the quality of deliveries.

These companies, located in the main Spanish cities, belong to different industries and manufacture various products, among which are soundproofing, metal stamping, welded parts, nuts and bolts, plastics (injection and moulded), mechanical sets and electrical products (see Table I).

Although this set of companies does not provide a representative sample of the population, the product manufactured or the process employed varies from plant to plant, providing some test of the generalization of the results.

The entire data obtaining process took place between March 1999 and July 200 I. All of the companies were observed over a period of 9 to 12 months and the following activities were carried out Montabon (2005):

- Step I: Selecting the line or process to be observed in the plant.

- Step 2: Initial diagnosis of the situation of the line selected. This diagnostic period usually lasted 2 days, with the collaboration of a group of 4 or 5 managers from different departments. During the visit, the measurements of the productive indicators published in the lines and their date of publication were also noted, where present. For occasional aspects, the head of quality control or maintenance was consulted for comparison with the opinion of the head of production.

- Step 3: Development of the Kaizen-Blitz activities and action. A workshop dynamic of 4-5 complete days duration was used, under the guidance of expert consultants. Groups of 5 to 14 people participated in the workshops, half of whom were workers. The contents were selected in line with the needs detected in the diagnosis. In these workshops, the theoretical concepts were introduced and the production lines were analysed in depth. The workshop participants were in charge of taking samples of the production indicator measurements, accompanying them with photos or video recordings when it was considered necessary. These data served to set out the initial value of the indicators prior to intervention of the adhoc group. At the end of the week, the group proposed to the management the actions to be taken over the next 3 months, which would be carried out by the team participants. Finally, a date was agreed for follow-up on the evolution of the indicators of productive efficiency. These data served to establish the final value of the indicators after the group's intervention.

This process was repeated 2 or 3 times in each company until the objectives specified in the initial diagnosis were fulfilled.

- Step 4: Drafting a report to reflect the summary of the activities, to be added to the research database.

Table I

Description of the companies studied

\begin{tabular}{|l|l|c|c|l|}
\hline & \multicolumn{1}{|c|}{ Processes } & $\begin{array}{c}\text { Turnover } \\
(\mathbf{m i l l} € \mathbf{)}\end{array}$ & $\begin{array}{c}\text { No. } \\
\text { employees }\end{array}$ & \multicolumn{1}{|c|}{ Industry } \\
\hline Case 1 & Injection and assembly & 28 & 250 & \multicolumn{1}{|c|}{ Plastics } \\
Case 2 & Pressing, mechanizing, injection and welding & 29 & 250 & Metal-mechanical \\
Case 3 & Pressing and welding & 80 & 400 & Metal-mechanical \\
Case 4 & Mechanizing, pressing and injection & 27 & 250 & Metal-mechanical \\
Case 5 & Injection & 24 & 250 & Plastics \\
Case 6 & Mechanizing and assembly & 60 & 600 & Assembly \\
Case 7 & Assembly & 85 & 250 & Assembly \\
Case 8 & Injection and assembly & 178 & 450 & Chemistry \\
Case 9 & Injection & 125 & 900 & Chemistry \\
Case 10 & Injection and assembly & 166 & 1,000 & Plastics \\
Case 11 & Injection and assembly & 85 & 900 & Electronic products \\
\hline
\end{tabular}




\subsection{Measures}

All the companies received the same intervention, summarised in the four steps described above in the data gathering process.

In order to create our dependent variables, we selected only production efficiency indicators gathered by objective measures. We considered that, for the research aims proposed, objective performance measures provide a more robust comparison, as they are less prone to short-term fluctuations Lowe et al. (1997). As our interest was centred on evaluating the impact on the production process, no financial indicators or indicators of human resources-related aspects were registered.

The five operational measures utilised to assess the efficiency of the productive process were as follows:

- Quality (Q) de Toni y Tonchia (1996), Giffi et al. (1990), Gunn (1992), Maskell (1995): percentage of correct pieces, compared with the total number of pieces processed.

- Overall Equipment Efficiency (OEE): Dal et al. (2000), Giffi et al. (1990), Maskell (1995): time in which the machine is working according to specifications producing correct pieces, compared with the total net time available.

- Dock to Dock Time (DTD): de Toni y Tonchia (1996), Giffi et al. (1990), Gunn (1992), Maskell (1995): average production time invested in raw materials, work in process and finished goods of a product.

- Workforce Productivity de Toni y Tonchia (1996), Giffi et al. (1990), Lowe et al. (1997): units produced per hour.

- ChangeoverTime Giffi et al. (1990), Gunn (1992), Maskell (1995), Schonberger (1996): time that a machine is stopped to make the necessary adjustments so that it can manufacture a different reference.

The absolute values of these operational measures can depend, among other factors, on the volume of production of the company, the capacity used, the type of process, or differences due to the complexity of products or time required to make them Banker et al. (1996), Cua et al. (2001), Ichniowski y Shaw (1999), Lowe et al. (1997). We should stress that none of these factors changed substantially in any of the companies during the observation period. To be able to compare the degree of improvement between the different companies we selected as dependent variables of our research the percentage that represented the improvement of the value of an indicator over the initial situation, i. e: $[1]$

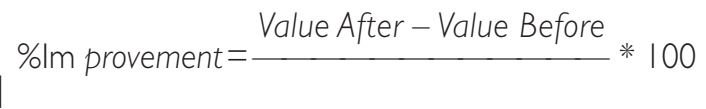

Value Before

\section{Results}

Before discussing the overall results of the companies analysed, we shall describe the state of the companies at the outset. We will begin by relating the production system in the different companies, in order to subsequently show the value of the operational measures in each of the companies before initiating the intervention of Kaizen-Blitz teams.

The production system in each plant was established on the basis of the data compiled during the interview and visit to the production facilities. We considered that most of the companies would either be at an initial early stage, which could be associated to a traditional point of view of mass production (cases 3 and 6), or else an initial stage in the development process towards lean production (cases 2, 4, 5, 7, 8, 9 and $\mid \mathrm{I}$ ). Company number I was at an intermediate stage of development and only company 10 seemed to have advanced to any degree in the lean production implementation process.

Regarding the initial situation of the productive indicators of each of the companies (Table 2), in the quality indicator most of the companies were below the recommended standards for world class manufacturing Dal et al. (2000). The lowest were cases 9 and 10 , due to the complexity of their processes.

As for OEE, only company 10 had a level close to $80 \%$, which may be considered a benchmark of world class manufacturing Dal et al. (2000), whereas the other companies were below the threshold that would be considered acceptable (60\%-75\%).

More than half of the companies have a dock to dock of more than 10 manufacturing days, thanks to which they are able to offset possible inefficiencies of their production lines. Companies 10, II and 4 had the highest dock to dock rate.

The workforce productivity is, apparently, acceptable 
Table 2

Operational performance at star-up

\begin{tabular}{|c|c|c|c|c|c|c|c|c|c|c|c|c|c|}
\hline \multirow{2}{*}{ Indicator } & \multirow{2}{*}{ Measure } & \multicolumn{11}{|c|}{ Case } & \multirow{2}{*}{ Mean } \\
\hline & & I & 2 & 3 & 4 & 5 & 6 & 7 & 8 & 9 & 10 & II & \\
\hline Quality (Q) & $\%$ & 91.2 & 82 & 78.3 & 93.2 & 97 & & & 76 & 55 & 71 & 90 & 81.5 \\
\hline $\begin{array}{l}\text { Overall Equipment } \\
\text { Efficiency (OEE) }\end{array}$ & $\%$ & 53 & 67 & 66 & 59 & 70 & & & 61 & 77.2 & 79 & 60 & 65.8 \\
\hline $\begin{array}{l}\text { Dock to Dock } \\
\text { Time (DTD) }\end{array}$ & Days & 6.9 & 13 & 8.2 & 23 & | 4.5 & 9 & & 17.8 & 10.6 & 39 & 37.6 & 19.2 \\
\hline $\begin{array}{l}\text { Workforce } \\
\text { Productivity }\end{array}$ & $\begin{array}{l}\text { Units/WF } \\
\text { hrs worked }\end{array}$ & 6.4 & 19.6 & 69 & 4,166 & 43.7 & 29.0 & 3.5 & 16.7 & & 4.3 & 13 & 437.0 \\
\hline $\begin{array}{l}\text { Batch Changeover } \\
\text { Time }\end{array}$ & Minutes & 18 & 35.5 & & 357 & 89 & 40 & & & 75 & 17 & 180 & 101.0 \\
\hline
\end{tabular}

and the variations are due to the different complexity of the products they manufacture (from screws or trims to complete car cop-pick).

As for changeover time, only two companies ( 10 and I) achieved reduced values. In the first case, the values reached are very close to the technological limit, as they were obtained after several SMED (single minute exchange of die) interventions. The remaining companies have a lot of room for improvement, particularly when we consider the high figures of companies 4 and II.

The empty boxes correspond to the indicators that were calculated in the companies in a way different to ours and we were unable to reconstruct the da- ta in a reliable manner.

The Table 3 shows how production indicators have improved in the cases studied.

All the productive indicators, on which interventions were made, were favoured by the use of lean production techniques derived from the activities developed by the ad-hoc groups

The main results obtained in the eleven cases analysed are summarised by a notable improvement in the efficiency of the machines (approximately 18\%), mainly obtained due to a radical improvement in the changeover time (reductions of almost $60 \%$ of the original time); improvement in the quality rate of ne-

Table 3

Improvement in operational performance

\begin{tabular}{|c|c|c|c|c|c|c|c|c|c|c|c|c|}
\hline \multirow{2}{*}{ Indicator } & \multicolumn{11}{|c|}{ Case } & \multirow{2}{*}{ Mean } \\
\hline & $\mathbf{I}$ & 2 & 3 & 4 & 5 & 6 & 7 & 8 & 9 & 10 & II & \\
\hline Quality (Q) & $8 \%$ & $5 \%$ & $11 \%$ & $6 \%$ & $1 \%$ & & & $1 \%$ & & & $5,6 \%$ & $5 \%$ \\
\hline $\begin{array}{l}\text { Overall Equipment } \\
\text { Efficiency (OEE) }\end{array}$ & $36 \%$ & $13 \%$ & $30 \%$ & $6 \%$ & $11 \%$ & & & $4 \%$ & & & $25 \%$ & $18 \%$ \\
\hline $\begin{array}{l}\text { Dock to Dock Time } \\
\text { (DTD) }\end{array}$ & & $-41 \%$ & $-48 \%$ & $-22 \%$ & $-7 \%$ & $-64 \%$ & & $-21 \%$ & & & $-60 \%$ & $-38 \%$ \\
\hline $\begin{array}{l}\text { Workforce } \\
\text { Productivity }\end{array}$ & $11 \%$ & $14 \% * *$ & $17 \% * *$ & $8 \%$ & & $34 \%$ & $60 \%$ & $23 \%$ & $9 \% * *$ & $21 \%$ & | $4 \% * *$ & $22 \%$ \\
\hline Batch ChangeoverTime & $-33 \%$ & $-72 \%$ & $-75 \% *$ & $-40 \%$ & $-7 \mid \%$ & & & $-54 \% *$ & $-48 \%$ & & $-87 \%$ & $-60 \%$ \\
\hline
\end{tabular}

The percentage of improvement was calculated as: (value at end-value at start//value at start. *Estimated as machine stop time reduction. *** Measured as direct workforce variation for a specific production instead of units per hour worked. 
arly 5\% (setting out from levels over $90 \%$ ); reduction of inventory levels by almost $40 \%$ and an increase in productivity between $9 \%$ and $60 \%$. Along with this, we also detected important improvements in the use of the space in the plant, a reduction in the number of containers and the distance travelled by products.

The quality indicator showed less gains, although it must be noted that almost all of the companies had already engaged in some sort of action to enhance their processes in order to assure acceptable quality levels. In fact, all of them were holders of the ISO9000 certificate and moreover had a certification from the customer, with annual audits and even in some cases with more demanding criteria than ISO-9000.

If we compare the quality levels of our companies with those of the companies supplying American automobile plants it may be seen that, initially (Table 2), the quality rating of almost all the observed companies was below 98\%, which is the average for North American companies Liker y Wu (2000). However, after the interventions, half of our companies reached a quality level of over $98 \%$. In addition, compared with the data of Lowe et al. (1997), the difference between the quality of the high performance companies and low performers is very small. In view of all the above, we considered that $5 \%$ of improvement obtained on average in the observed companies is a significant figure.

Regarding the productivity indicator, the measurement used by Lowe et al. (1997) is not the same as ours, which is why we cannot directly compare their data with ours. Nevertheless, it is highly illustrative to verify the broad margin of variation in productivity values between companies making different products, a factor that may also be observed in our cases.

Unfortunately, we were unable to find any published material with data that would allow us to compare the values obtained for the rest of the indicators studied in our research.

Finally, we must take into account that the presented measures are not independent. For example, an improvement of quality in automated processes will affect the efficiency of the machines. Efficiency is also affected by the reduction in changeover time, because depending on the extent of the reduction, more machine manufacturing time can be obtained. Nevertheless, this is not a direct relationship, because the company can take advantage of the fact that changeover is faster to make more changes. In this case, machine use will not be improved, but the in- dicator that would be enhanced is dock to dock, since the work in progress would be less when working with smaller batches. As an example, we can see that in the case of company 4 (Table 3 ) the improvement of $6 \%$ in OEE is due to the improved quality of the products, while the $40 \%$ reduction in changeover time did not improve efficiency, as the company policy was to cut the size of the batches. What did improve in this case was the dock to dock indicator (22\%), which meant that, on average, the products were in the plant for one week less (falling from 23 days to 18 days).

\section{Discussion and Conclusions}

Our work aims to identify the possibilities for improvement of the productive indicators when a company puts in action Kaizen-Blitz activities. The companies studied belonging to different sectors and production processes, were medium to large sized and their main clients are automobile assembly plants.

All our companies have initiated measures to improve performance and, in the light of the results obtained, they appear to have fulfilled this objective, at least as far as production indicators are concerned.

One important aspect for the smooth running of the interventions were the support shown by the managers in the ad-hoc group meetings and the presence of the CEO at the closing session of each workshop. In addition, the workshops gave rise to a structure that facilitates communication between the group and management, while the training acts as a means to reduce resistance to change Power y Sohal (2000).

As limitations of this work, the fact that 16 (29\%) of the boxes of the Table 3 are blank may be significant. The main cause of this was the cost to the company of providing the data that enabled us to calculate the indicators or, as in the case of company 7, policies of confidentiality that prevented our access to the data. On the other hand, in some companies inconsistent data appeared, depending on the source that had provided them (production department, quality or maintenance). For this reason, during our intervention in the initial workshop we had to trace the necessary data. This was carried out together with the components of the ad-hoc group, under the supervision of the training consultants. These data were compared with diverse sources or were directly taken in plant when divergences arose. This process took up almost two days of work in each company and required the participation of several managers, 
usually those occupying key positions in maintenance, quality and production. Therefore, to avoid resistance, in each factory we limited ourselves to obtaining the measures of the indicators that were of immediate practical use to them, taking into account the needs detected in the initial diagnosis, the training actions implemented and the changes introduced in the production lines.

Another limitation of this study is the issue of the generalization of the findings. In some sense we have tried to overcome this limitation by analysing a number of production lines that varied in terms of product manufactured, size, annual turnover, production process used and starting level of lean deployment. However, the study should be complemented taking other sectors into account, where the companies supply a high number of clients with fluctuating and not very predictable demands. On the other hand, since all the companies received the same intervention, consisting of lean deployment through workshops, we cannot compare the results that would be obtained with another type of interventions. The lack of such data prevents us from making a definitive causal attribution.

An important advantage of our work was obtaining data from multiple sources (interviews, observations and documentation analysis), giving a certain degree of confidence in the results Yin (1994). The interviews were carried out formally in the diagnostic sessions and the production managers took part. The line observation was done in the initial diagnosis and during workshop development. The records of production, quality and maintenance departments were also consulted, to compare them with the line observations made during the workshops. With the data sampling methodology selected, this task was laborious and demanded great dedication by the researchers. For this reason, adapting to the resources available, in our research design we chose to observe a limited number of cases.

\section{Implications for research and practice}

The issue approached in this paper is important for company and production managers because it shows the potential gains that can be obtained by means of Kaizen-Blitz like those described in this research.

We consider that the use of training-intervention dynamics of short duration, attended by people from different hierarchic levels and different departments, related to a production line or process, could contribute to improve the productive results. The ses- sions should incorporate both ice-breakers dynamics, to create an atmosphere that encourages problemsolving in groups, and the philosophy and methodology of the lean tools to be implemented. During the sessions, it is also necessary to set aside time for «capturing» the necessary data, analysing them and proposing alternatives for the improvement. It is recommended that these sessions be guided by experts in the application of the tools and that they supervise the data gathering and the activities of the group.

It is advisable that at the end of the week a plan be agreed upon and, if possible, that the participants should make a presentation of it to the company management, to corroborate their acceptance and obtain a commitment for the dates from everyone involved.

Our paper may be interesting too for the people involved in consulting tasks. These can justify the investment made by the company to start up the interventions, with the gains expected from the application of their services.

In order to continue the research, we propose the following actions that would complement our work: Increasing the number of companies receiving the treatment, in order to have several firms at every level of the control variables (sector, production process, product, lean production development stage prior to the intervention); incorporating companies that have not received treatment (Kaizen-blitz), both those that have never received it at all and those that have at one time, but have been some time without receiving treatment; and incorporating as variables the levels of safety and hygiene, stress or the workload of line workers, to find out if the increase in productivity is due to the worsening of these conditions, as diverse authors propose Fairris (2002).

In conclusion, the results obtained in our research underline the effectiveness of the use of Kaizen-Blitz in automotive industry. We are confident that this study provides proof that may encourage other companies to start similar processes that facilitate the improvement of their results.

\section{References}

BANKER, R. D.; FIELD, J. M.; SCHROEDER, R. G., and SINHA, K. K. ( I 996). Impact of work teams on manufacturing performance: A longitudinal field study Academy of management Journal, Vol. 39, 4.

COONEY, R. (2002). Is «lean» a universal production system? Batch production in the automotive 
industry International Journal of Operations \& Production Management, Vol. 22, 9- 10.

CUA, K.; MCKONE, K, and SCHROEDER, R. G. (200I). Relationships between implementation of TQM, IIT, and TPM and manufacturing performance Journal of Operations Management, Vol. 19,6.

DAL, B.;TUGWELL, P., and GREATBANKS, R. (2000). Overall equipment effectiveness as a measure of operational improvement - A practical analysis International Journal of Operations \& Production Management, Vol. 20, 12.

DETONI, A., and TONCHIA, S. ( 1996). Lean organization, management by process and performance measurement International Journal of Operations \& Production Management, Vol. 16, 2.

FAIRRIS, D. (2002). Are transformed workplaces more productively efficient? Journal of Economic Issues, Vol. 36, 3.

FULLERTON, R. R.; MCWATTERS, C.L S., and FAWSON, C. (2003). An examination of the relationships between JIT and financial performance Journal of Operations Management, Vol. 21, 4.

GIFFI, C.; ROTH, A., and SEAL, G. ( 1990). Competing in worl-class manufacturing Irwin.

GLASSOP, L. (2002). The organizational benefits of teams Human relations, Vol. 55, 2,

GUNN,T,H. (1992), 2 I st century manufacturing: creating winning business performance OMNEO,

HACKMAN, J. R. ( 1990), Groups that work Jossey-Bass,

ICHNIOWSKI, C., and SHAW, K. (I 999). The effects of human resource management systems on economic performance: An international comparison of US and Japanese plants Management Science, Vol. 45, 5.

LAWLER III, E. E. ( 1 996). La ventaja definitiva Granica. LAWLER III, E. E., MOHRMAN, S., and BENSON, G. (200I). Organizing for high performance: employee involvement, TQM, reengineering, and knowledge management in the fortune 1000. The CEO report Jossey-Bass.

LIKER, J. K., and WU, Y.-C. (2000). Japanese automakers, U.S. Suppliers and supply-chain superiority MIT Sloan Management Review, Vol. 42, I.
LOWE, J.; DELBRIDGE, R., and , N. (1997). High-Performance Manufacturing - Evidence from the Automotive Components Industry Organization Studies, Vol. I 8, 5

MARIN, F., and DELGADO,J. (2000). Las técnicas justo a tiempo y su repercusión en los sistemas de producción Economía industrial, 331.

MARTINEZ SANCHEZ, A., and PEREZ PEREZ, $M$. (200I). Lean indicators and manufacturing strategies International Journal of Operations \& Production Management, Vol. 2 I , I I.

MASKELL, B. (1995). Sistemas de datos de industrias de primer nivel mundial TGP-Hoshin.

MONTABON, F. (2005). Using kaizen events for back office processes: the recruitment of frontline supervisor co-ops Total Quality Management \& Business Excellence, Vol. 16, 10.

MOSES, T. P., and STAHELSKI, A. J. ( 1999). A productivity evaluation of teamwork at an aluminum manufacturing plant Group \& Organization Management, Vol. 24, 3.

POWER, D. J., and SOHAL, A. S. (2000). Human resource management strategies and practices in Just-In-Time environments: Australian case study evidence Technovation, Vol. 20, 7.

REES, F. (1997). Teamwork from start to finish: 10 steps to results Pfeiffer- Jossey-Bass.

SCHONBERGER, R. J. ( 1996). World Class Manufacturing: the next decade Free Press.

SHAH, R., and WARD, P T. (2003). Lean manufacturing: context, practice bundles, and performance Journal of Operations Management, Vol. 2 I, 2.

TAIRA, K. ( 1996). Compatibility of human-resource management, industrial-relations, and engineering under mass-production and lean production: an exploration Applied Psycholoy - an International review, Vol. 45, 2.

WHITE, R. E.; PEARSON, J. N., and WILSON, J. R. ( 1999). IIT manufacturing: A survey of implementations in small and large U.S. manufacturers Management Science, Vol. 45, I.

WOMACK, J. P.; JONES, D. T., and ROOS, D. (1992). La máquina que cambió el mundo I McGraw-Hill 